\title{
TAXONOMIA DO GÊNERO Albizia (LEGUMINOSAE) NO ESTADO DE MATO GROSSO, BRASIL
}

Aparecida Silveira da Silva ${ }^{1}$, José Martins Fernandes ${ }^{2}$, Célia Regina Araújo Soares Lopes $^{3}$

${ }^{1}$ Graduanda em Licenciatura e Bacharelado em Ciências Biológicas, UNEMAT, Campus Universitário de Alta Floresta, Mato Grosso.

${ }^{2}$ Professor da Faculdade de Ciências Biológicas e Agrárias (Orientador), UNEMAT, Campus Universitário de Alta Floresta, Mato Grosso. E-mail: fernanbio@bol.com.br

${ }^{3}$ Professora da Faculdade de Ciências Biológicas e Agrárias (Coorientadora).

UNEMAT, curadora do HERBAM, Campus Universitário de Alta Floresta, Mato Grosso.

Recebido em: 06/04/2019 - Aprovado em: 10/06/2019 - Publicado em: 30/06/2019 DOI: 10.18677/EnciBio_2019A150

\section{RESUMO}

O trabalho apresenta o estudo taxonômico do gênero Albizia (Leguminosae) no estado de Mato Grosso, Brasil, realizado entre os meses de Junho de 2018 à março de 2019, no Laboratório de Morfologia Vegetal do Herbário da Amazônia Meridional (HERBAM), localizado no município de Alta Floresta, Mato Grosso, baseado em espécimes coletados na região e/ou depositados no HERBAM. O trabalho apresenta chave de identificação para às sete espécies que ocorrem no estado, seis nativas (A. decandra, $A$. duckeana, $A$. inundata, $A$. niopoides, $A$. pedicellaris, $A$. subdimidiata) e uma introduzida ( $A$. lebbeck), diagnoses e/ou sinopses morfológicas, fotos e distribuição geográfica para as espécies. Amplia a distribuição geográfica de A. duckeana, tornando-se o estado de Mato Grosso com o maior número de espécies nativas no Brasil, junto com os estados do Amazonas, Pará e Paraná. Assim, Mato Grosso, mantém 60\% das espécies do gênero no Brasil.

PALAVRAS-CHAVE: Amazônia, Ingeae, Morfologia.

\section{TAXONOMY OF THE GENUS Albizia (LEGUMINOSAE) IN THE STATE OF MATO GROSSO, BRAZIL}

\begin{abstract}
This work presents the taxonomic study of the genus Albizia (Leguminosae) in the state of Mato Grosso, Brazil, carried out between the months of June 2018 and March 2019, in the Laboratory of Plant Morphology of the Herbário da Amazônia Meridional (HERBAM), located in the municipality of Alta Floresta, Mato Grosso, based on specimens collected in the region and /or deposited in HERBAM. The work presents identification key for the seven species that occur in the state, six native $(A$. decandra, A. duckeana, $A$. inundata, $A$. niopoides, $A$. pedicellaris, $A$. subdimidiata)
\end{abstract}


and one introduced ( $A$. lebbeck), diagnoses and / or morphological synopses, photos and geographic distribution for the species. It broadens the geographical distribution of $A$. duckeana, becoming the state of Mato Grosso with the largest number of native species in Brazil, along with the states of Amazonas, Pará and Paraná. Thus, Mato Grosso, maintains $60 \%$ of the species of the genus in Brazil.

KEYWORDS: Amazon, Ingeae, Morphology.

\section{INTRODUÇÃO}

A família Leguminosae é a terceira maior dentre as Angiospermas, sendo constituída por aproximadamente 19.581 espécies e 765 gêneros, distribuídos em sete subfamílias, Duparquetioideae, Cercidoideae, Detarioideae, Dialioideae, Caesalpinioideae e Papilionoideae, sendo que Caesalpinioideae inclui os táxons de Mimosoideae, no clado mimosoide (LPWG, 2017; APW, 2019).

Apresenta ampla importância econômica, superada apenas por Poaceae, devido à alta produção de sementes, legumes, folhas, raízes e flores, destacando-se na produção de proteína vegetal, produção de óleos, resinas, medicamentos, inseticidas e forragem (JUDD et al., 2009). Destaca-se, na agricultura, pela sua capacidade de fixação de nitrogênio em decorrência da simbiose com bactérias, principalmente do gênero Rhizobium, que resultam na melhoria de solos, e como a produção agrícola global deverá dobrar até 2050 para atender à demanda projetada por alimentos e fibras (FERNANDES et al., 2014; FERNANDES et al., 2016a; ADAMS et al., 2016; SPRENT et al., 2017), Leguminosae com sua ampla riqueza em espécie, diversidade de uso e capacidade de fixação de nitrogênio, torna-se, cada vez mais, um grupo taxonômico importante para as futuras gerações.

Com uma distribuição cosmopolita, a família está bem representada desde os trópicos até regiões temperadas e apresenta várias formas de vida como ervas, trepadeiras, subarbustos, arbustos, árvores e lianas (JUDD et al., 2009; ADAMS et al., 2016). A família é reconhecida por apresentar folha composta, alterna e com pulvino, uma pétala adaxial diferenciada, placentação marginal e fruto do tipo legume (CHAPPILL, 1995).

No Brasil ocorrem 2.849 espécies e 222 gêneros, presentes em quase todas as fitofisionomias brasileiras (BFG, 2018). A família se destaca no Cerrado, com 135 gêneros e 1.262 espécies; Amazônia, com 167 gêneros e 1.148 espécies; Mata Atlântica, com 154 gêneros e 1.005 espécies e Caatinga, com 127 gêneros e 613 espécies (BFG, 2018). Mato Grosso está representado por 122 gêneros e 616 espécies (BFG, 2018), no entanto, estudos vem contribuindo com à ampliação da riqueza da família no estado, principalmente para o domínio fitogeográfico da Amazônia (FERNANDES et al., 2015; FERNANDES et al., 2016b; SILVA et al., 2016; FERNANDES et al., 2016c; SOUZA et al., 2016; ABREU et al., 2018), com espécimes depositados no Herbário da Amazônia Meridional (HERBAM), localizado no município de Alta Floresta (LOPES, 2015).

Dentre os gêneros de Leguminosae com ocorrência no Brasil está Albizia Durazz (BFG, 2018). O gênero foi publicado por Durazzini em 1772 e possui distribuição pantropical (ARCE et al., 2008). As espécies possuem folhas bipinadas, nectários na base ou região mediana do pecíolo, entre ou pouco abaixo do primeiro par de pina e, frequentemente, entre os pares distais de pinas e foliólulos, sésseis ou subsésseis, geralmente pateliformes, planos, cupuliformes, verruciformes ou capitados; foliólulos com nervação palminérvea ou peninérvea; unidades de inflorescências capituliformes ou umbeliformes reunidas em fascículos, panículas ou 
pseudo-racemos, axilares ou terminais; flores dimórficas ou homomórficas, 5-6 meras; pouco a muitos estames; disco nectarífero presente ou ausente; fruto folículo, legume ou criptolomento; sementes monocolores, testa óssea, pleurograma aberto ou fechado (FERNANDES, 2011).

O gênero possui entre 120 e 140 espécies, principalmente arbóreas (LEWIS e RICO ARCE, 2005; BOUAZIZ et al., 2016). No Brasil, está representado por 10 espécies nativas, com centro de diversidade na Amazônia (7 espécies), Mata Atlântica (6 espécies) e Cerrado (4 espécies); o estado de Mato Grosso está representado por cinco espécies, são elas Albizia decandra (Ducke) Barneby \& J.W. Grimes, Albizia inundata (Mart.) Barneby \& J.W. Grimes, Albizia niopoides (Spruce ex Benth.) Burkart, Albizia pedicellaris (DC.) L. Rico e Albizia subdimidiata (Splitg.) Barneby \& J.W. Grimes (BFG, 2018).

Algumas espécies podem ser utilizadas para fins de ornamentação, restauração florestal, melhorar a qualidade do solo e como alimento para animais (SILVA; SOUZA-LIMA, 2013). O trabalho apresenta o estudo taxonômico do gênero Albizia (Leguminosae) no Estado de Mato Grosso, baseado na coleção do HERBAM e literaturas especializadas, com chave de identificação, diagnoses, sinopses, fotos, distribuição geográfica e nome popular para as espécies.

\section{MATERIAL E MÉTODOS}

O trabalho foi baseado em exsicatas depositadas no Herbário da Amazônia Meridional (HERBAM) e coletas complementares na região de Alta Floresta, Mato Grosso, entre os meses de Junho de 2018 à março de 2019. O HERBAM está localizado na MT 208, Km 146, № S/N - Bairro Jardim Tropical, Universidade do Estado de Mato Grosso, Câmpus de Alta Floresta, Mato Grosso, Brasil.

Para cada indivíduo amostrado, foram coletados em média cinco ramos com folhas, flores e/ou frutos e herborizados no HERBAM. Foram identificados a partir de literatura especializada (BARNEBY; GRIMES, 1996; FERNANDES, 2011), registrados e depositados no acervo do HERBAM.

Diagnoses morfológicas com base em caracteres vegetativos e reprodutivos foram realizadas no Laboratório de Morfologia Vegetal do HERBAM, a partir de materiais de Albizia depositados no acervo e/ou provenientes de coletas na região. A terminologia empregada nas diagnoses foi baseada em Radford et al. (1974), exceto para os nectários extraflorais que está de acordo com Fernandes (2011) e frutos e sementes, conforme Barroso et al. (1999). As espécies com ocorrência no estado, mas sem espécimes depositados no HERBAM, tiveram sinopses apresentadas baseadas em Barneby e Grimes (1996) e Fernandes (2011).

A chave para identificação das espécies com ocorrência no Estado de Mato Grosso foi baseada nos materiais examinados do HERBAM, Barneby e Grimes (1996), Fernandes (2011) e BFG (2018).

\section{RESULTADOS E DISCUSSÃO}

O trabalho inclui Mato Grosso entre os estados do Brasil com maior riqueza em espécies nativas do gênero Albizia, com seis espécies, dentre elas, $A$. duckeana, uma nova ocorrência para o estado. Segundo BFG (2018) os estados do Amazonas, Pará e Paraná, também possuem seis espécies cada. O Herbário da Amazônia Meridional (HERBAM), importante coleção do estado, mantém exsicatas de cinco espécies de Albizia ( $A$. duckeana, $A$. lebbeck, $A$. niopoides, $A$. pedicellaris, $A$. subdimidiata). 
As espécies $A$. decandra e $A$. inundata ocorrem no Mato Grosso (BFG, 2015; $B F G, 2018)$, mas não têm espécimes depositados no HERBAM. A única espécie introduzida no estado é $A$. lebbeck, trazida do continente africano devido à sua importância em sistemas agrícolas. As principais semelhanças e diferenças morfológicas entre as espécies de Albizia que ocorrem no Estado de Mato Grosso estão apresentadas na chave de identificação a seguir.

\section{Chave para identificação das espécies de Albizia em Mato Grosso}

\section{Pinas 1-4 pares}

2. Foliólulos $11-21 \mathrm{~mm}$ largura; fruto do tipo legume, largos, $2,5-4,5 \mathrm{~cm}$ largura lebbeck

4. Albizia

2'. Foliólulos 3,5-9 mm largura; frutos do tipo criptolomento, legume nucóide ou legume, estreitos, 0,9-2,1 cm largura

3. Foliólulos oblongo-elípticos; fruto legume nucóide

Albizia

decandra

3'. Foliólulos lanceolados ou estreitamente ovados; fruto criptolomento ou legume

4. Ápice dos foliólulos agudo, fruto criptolomento

4'. Ápice dos foliólulos obtuso, fruto legume

7. Albizia subdimidiata

1'. Pinas 6-15 pares

5. Foliólulos 38-55 pares, fruto legume

5. Albizia niopoides

5'. Foliólulos 18-31 pares, fruto folículo

6. Pecíolo puberulento, não dourado; cálice 2-2,2 $\mathrm{mm}$ comprimento, corola $5,1-5,6 \mathrm{~mm}$ comprimento ....................... 6. Albizia pedicellaris

6'. Pecíolo tomentoso, dourado; cálice 6-7 mm comprimento, corola 14$15 \mathrm{~mm}$ comprimento duckeana

2. Albizia

1. Albizia decandra (Ducke) Barneby \& J.W.Grimes. Figura 1.

A espécie ocorre no Estado de Mato Grosso (BFG, 2018), porém, não está depositada no HERBAM. De acordo com Barneby e Grimes (1996), são árvores 2030 metros de altura; folhas 1-3 pares de pinas, pecíolo 2-5 cm compr., foliólulos 9-13

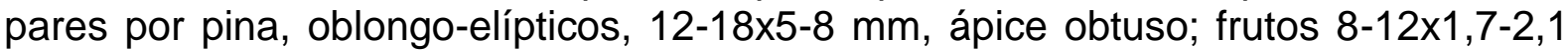
$\mathrm{cm}$. De acordo com a descrição do fruto apresentada por Barneby e Grimes (1996), se enquadra como um legume nucóide conforme a classificação de Barroso et al. (1999). 


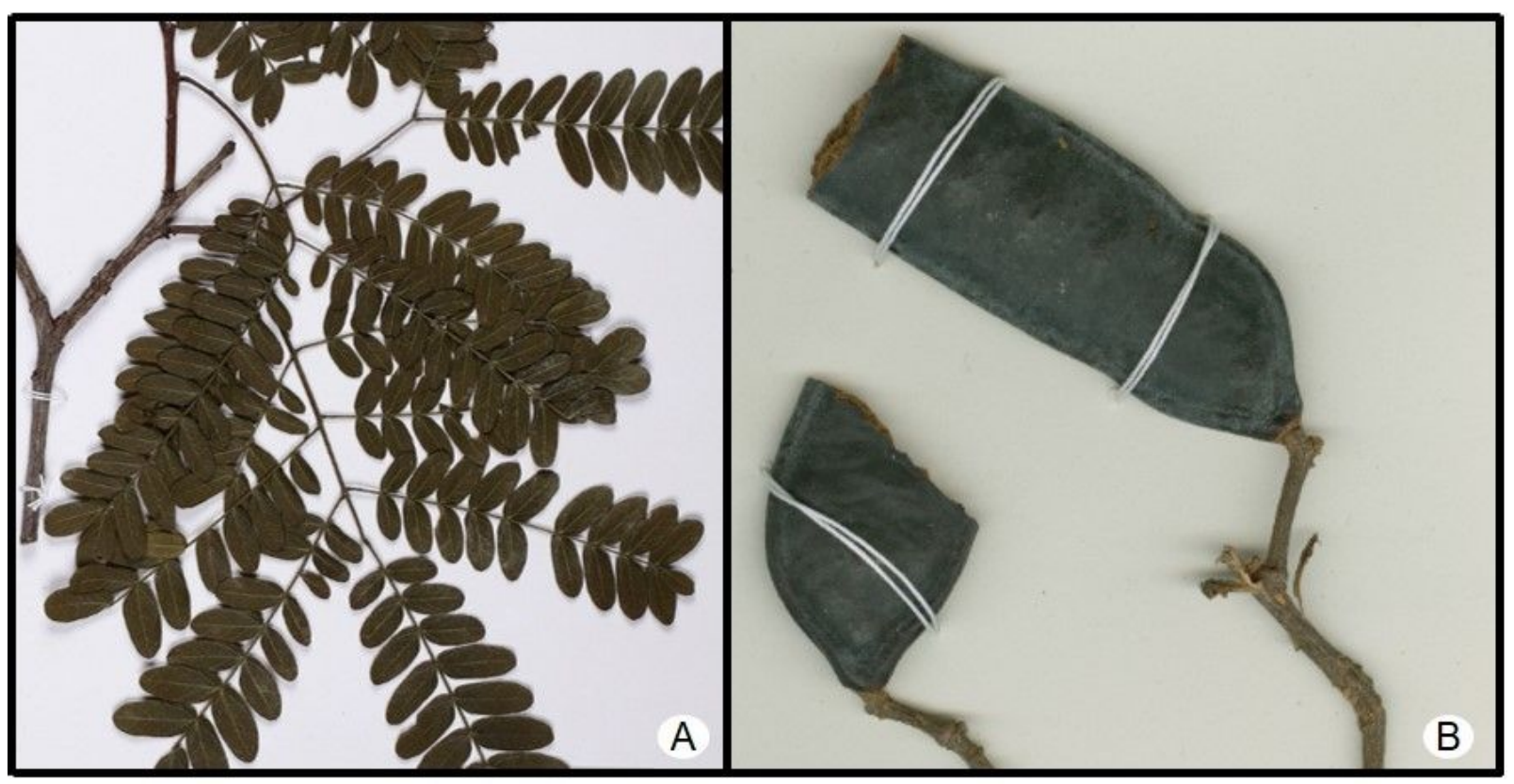

FIGURA 1. Albizia decandra: A, folhas (foto adaptada, RB 452.792); B, partes de frutos (foto adaptada, RB 10174).

A espécie é endêmica do Brasil (BARNEBY; GRIMES, 1996), com ocorrência na região Norte, nos estados do Amazonas, Amapá e Pará, e no Centro-Oeste, no estado de Mato Grosso, sob domínio fitogeográfico da Amazônia, em floresta de terra firme (BFG, 2018).

\section{Albizia duckeana L. Rico, Kew Bull. 55(2): 404. 2000. Figura 2.}

Árvores, $25 \mathrm{~m}$ alt. Folhas 10-12 pares de pinas; pecíolo 1,5-4 cm compr., tomentoso; nectário pouco abaixo do primeiro par de pina e, geralmente entre os 3-4 últimos pares de pinas, sésseis, verruciformes, elípticos; raque 8-11 cm compr., tomentosa; foliólulos 18-30 pares por pina, 6-10x1,5-2,5 mm, estreitamente elípticos ou lanceolados, base assimétrica, ápice arredondado ou obtuso, faces adaxial e abaxial esparso seríceas. Unidades de inflorescências umbeliformes, isoladas ou reunidas em fascículos, axilares ou terminais; brácteas caducas; flores dimórficas. Flores laterais pediceladas, pedicelo 9,8-14 mm compr.; cálice 5-5,5 mm compr., campanulado, tomentoso; corola 8-10,3 mm compr., campanulada tomentosa; androceu 24-28 estames, $25-40 \mathrm{~mm}$ compr., tubo 4-4,5 mm compr., incluso; disco nectarífero ausente; ovário 2,5-3 $\mathrm{mm}$ compr., tomentoso. Flores terminais pediceladas, 1-2 por inflorescência, pedicelo 3-4 $\mathrm{mm}$ compr.; cálice 6-7 $\mathrm{mm}$ compr., tubuloso, tomentoso; androceu 39 estames, $28 \mathrm{~mm}$ compr., tubo $19 \mathrm{~mm}$ compr., exserto; disco nectarífero ausente; ovário 2,5-3 mm compr., tomentoso. Folículos 8$10 \times 2-2,5 \mathrm{~cm}$, estreitamente elípticos, lenhosos, sem suturas transversais, margens expandidas, nervuras transversais irregulares e entrelaçadas, glabros; 9-11 sementes, imaturas. 


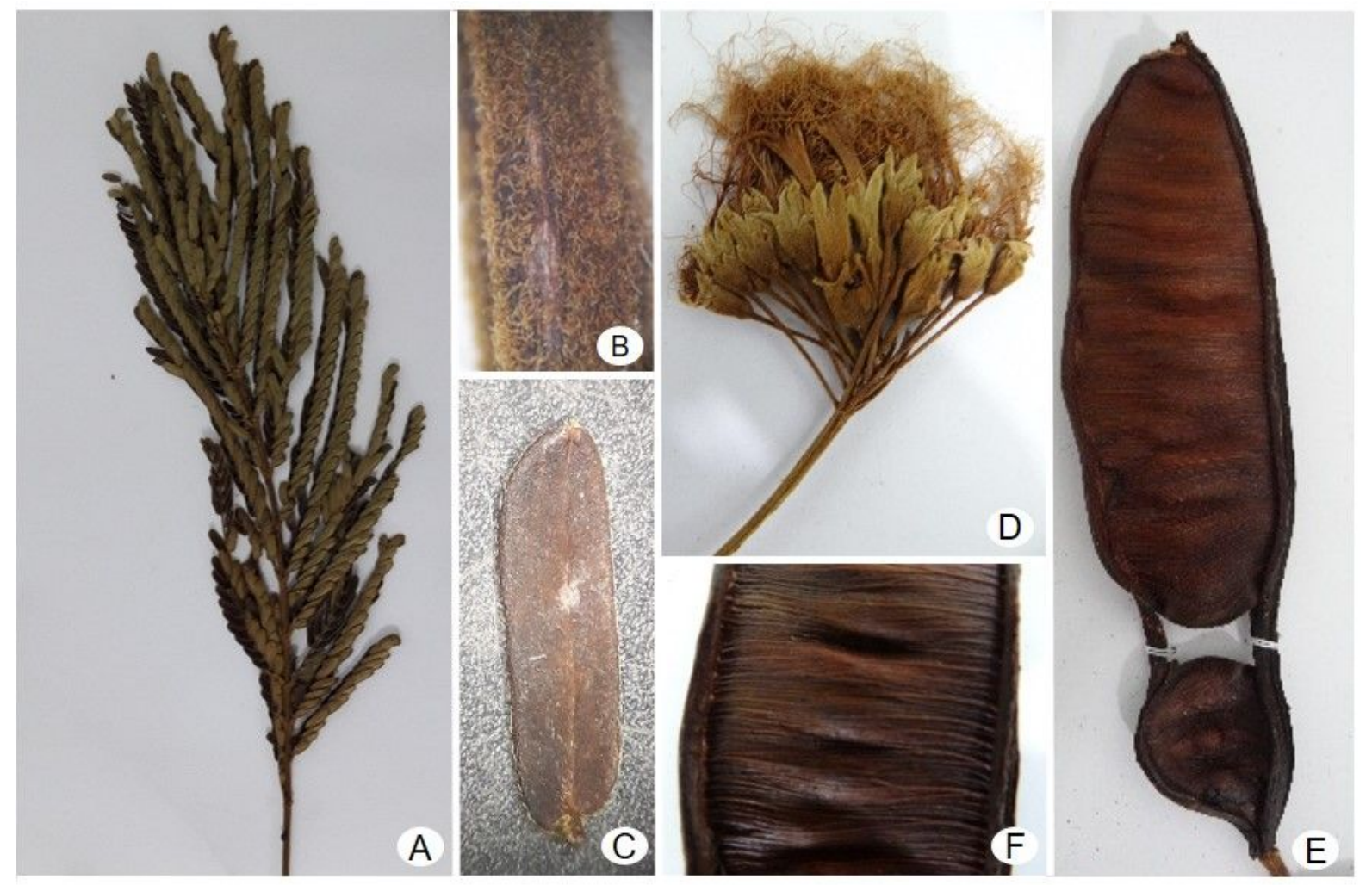

FIGURA 2. Albizia duckeana: $A$, folha; $B$, indumento do pecíolo; C, foliólulo; D, inflorescência; $E$, fruto; $F$, detalhe do fruto com nervuras transversais irregulares e entrelaçadas.

A espécie não é endêmica do Brasil (BARNEBY; GRIMES, 1996). No Brasil ocorre a região Norte do Brasil, nos estados do Acre, Amazonas, Amapá, Pará e Rondônia, sob domínio fitogeográfico da Amazônia (BFG, 2018). O presente trabalho amplia a sua distribuição geográfica ao estado de Mato Grosso, região Centro Oeste do Brasil.

Material examinado: Mato Grosso. Paranaíta: UHE São Manoel, 28/V/2009, fl., C. R. A Soares et al. 2258 (HERBAM). Novo Mundo: Parque Estadual do Cristalino, 03/VI/2007, fr., D. Sasaki 1751 (HERBAM).

3. Albizia inundata (Mart.) Barneby \& J.W.Grimes, Mem. New York Bot. Gard. 74(1): 238. 1996. Figura 3.

A espécie ocorre no Estado de Mato Grosso (BFG, 2018), no entanto, não está depositada no HERBAM. De acordo com Barneby e Grimes (1996) são árvores 3-14 metros de altura; folhas 2-4 pares de pinas, pecíolo 3-8 cm compr., foliólulos 8-14 pares por pina, lanceolados ou estreitamente ovados, 15-28x3,5-9 mm, ápice agudo; fruto criptolomento, 9-18x0,9-1,4 cm, margens sinuosas.

A espécie não é endêmica do Brasil (BARNEBY; GRIMES, 1996). No Brasil ocorre na região Norte, nos estados do Amazonas, Pará, Roraima e Tocantins, no Nordeste, nos estados de Alagoas, Bahia, Ceará, Maranhão, Paraíba, Pernambuco, Piauí, Rio Grande do Norte e Sergipe, no Centro-Oeste, nos estados de Goiás, Mato Grosso do Sul e Mato Grosso, no Sudeste, nos estados de Minas Gerais e São Paulo, e no Sul, nos estados do Paraná e Rio Grande do Sul (BFG, 2018). 

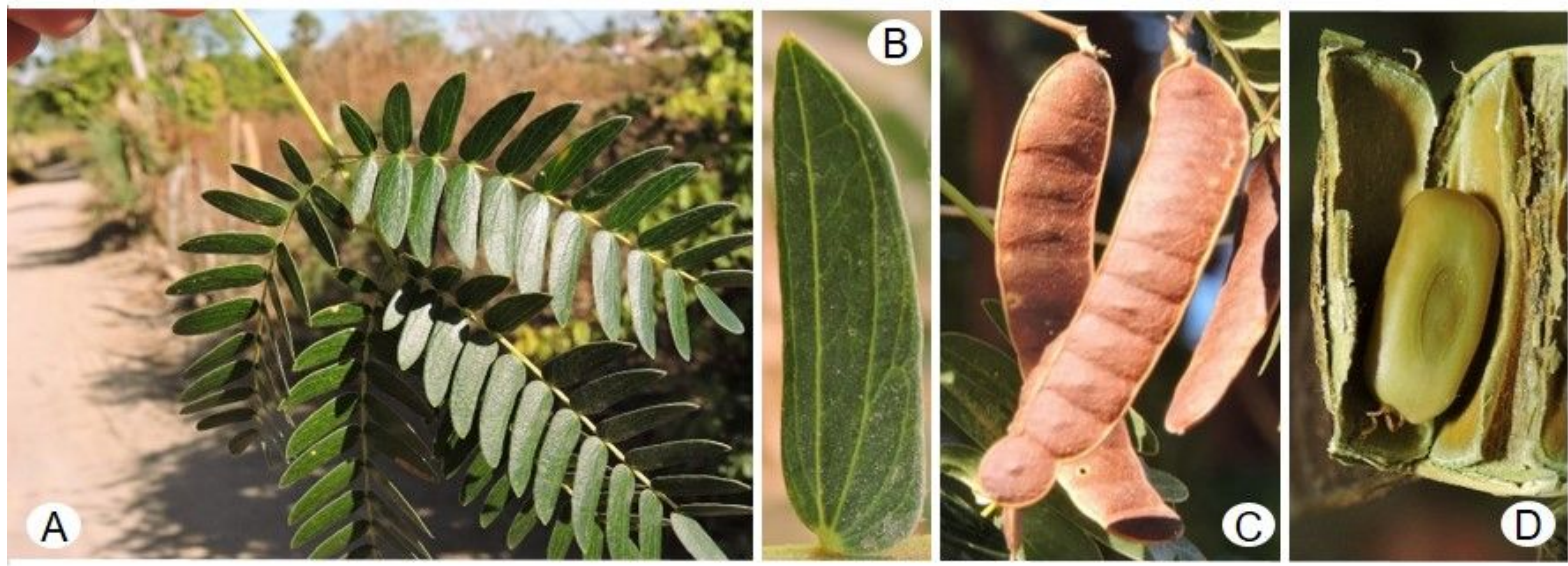

FIGURA 3. Albizia inundata: A, folha; B, foliólulo; C, frutos; D, artículo do fruto (fotos G-J: R.T. Queiroz).

4. Albizia lebbeck (L.) Benth., London J. Bot. 3: 87. 1844. Figura 4.

Árvores, 8-10 m alt. Folhas 2-4 pares de pinas; pecíolo 3-9 cm compr., esparso tomentoso; nectário na base do pecíolo e, as vezes, pouco baixo do primeiro e do último par de pina, sésseis, planos, raramente cupuliformes, elípticos; raque 2,5-11 cm compr., esparso tomentoso; foliólulos 3-7 pares por pina, 3,6-4,9x1,1-2,1 cm oblongos, base obtusa, ápice arredondado ou retuso, faces adaxial e abaxial esparso seríceas. Unidade de inflorescências umbeliformes, reunidas em fascículos terminais ou axilares; pedúnculos 4,5-8 cm compr., brácteas 0,2-0,4×0,1-0,2 mm, triangulares a lanceoladas; flores homomórficas, sésseis ou pediceladas, $0,4 \mathrm{~mm}$ compr.; gamossépalo, 3-5mm compr. infundibuliforme, puberulento; corola 4-8 mm compr., campanulada, glabra, lacínios puberulentos; androceu 18-24 estames, 2,5-3 cm compr., base branca, ápice esverdeado, tubo 2,5-3,5 mm compr., incluso; disco nectarífero ausente; ovário 2,5 mm compr., glabro, estilete 2,4-2,7 cm compr., estigma punctiforme. Legumes $12-23,5 \times 2,5-4,5 \mathrm{~cm}$, margens levemente sinuosas, não moniliformes, linear ou estreitamente elípticos, glabros, ápice e base agudos; 49 sementes 8-11x6-9 mm, circulares ou elípticas, marrom, pleurograma aberto, formato U.
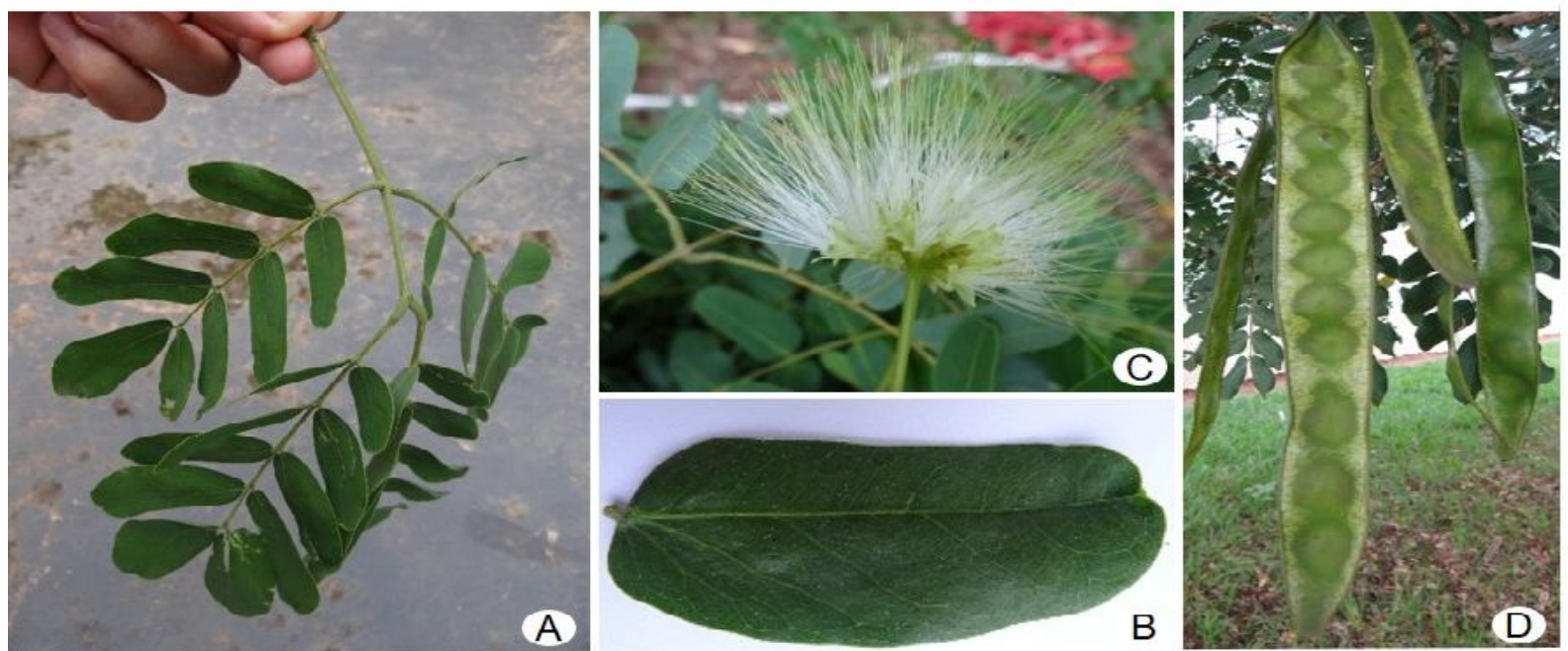

FIGURA 4. Albizia lebbeck: A, folha; B, foliólulo; C, inflorescência; D, frutos. 
A espécie é nativa na região Leste da Ásia e, devido à importância agrícola, possui distribuição pantropical, com ocorrência na África, Oceania, parte da Ásia e nas Américas do Norte, Central e do Sul (BARNEBY; GRIMES, 1996).

Albizia lebbeck pode ser utilizada no tratamento de disenteria, hemorróidas, hanseníase, etc. (SHIRODE et al., 2008); extrato alcoólico e/ou hidroalcoólico tem eficácia como anticonvulsivante, sedativo, anti-inflamatório, antitumoral, antifúngico, atividade antibacteriana e antiparasitária (BARBOSA, 2014).

Material examinado: Mato Grosso. Alta Floresta: entrada da cidade ao lado da empresa Agro Amazônia, 20XI2018, fl. A. S. S. Silva 03 \& J. M. Fernandes (HERBAM), 20XI2018, fr. A. S. S. Silva 04 \& J. M. Fernandes (HERBAM).

5. Albizia niopoides (Spruce ex Benth.) Burkart var. niopoides, Legum. Argent. (ed. 2) 542. 1952. Figura 5.

Árvores, 10-15 m alt. Folhas 7-15 pares de pinas; pecíolo 2,5-4,2 cm compr., puberulento; nectários na região mediana do pecíolo e, as vezes entre o último par de pina, sésseis, cupuliformes, circulares ou elípticos; raque 8-13 cm compr., puberulenta; foliólulos 38-55 pares por pina, 6-8x1,5-2 mm, lanceolados, base truncada, ápice agudo, faces adaxial e abaxial glabras, margens ciliadas, nervura principal excêntrica. Unidades de inflorescência capituliformes, reunidas em panículas ou fascículos, axilares ou terminais; pedúnculos 8-9 mm, compr., brácteas 0,4-0,5x0,3-0,4 mm, ovadas, puberulentas, $8-9 \mathrm{~mm}$, compr.; flores sésseis ou subsésseis; cálice 1,5-1,9 mm compr., campanulado, pubescente; corola 3,1-3,3 mm compr., campanulada, glabra; lacínios puberulentos; androceu 20-27 estames, 7-8 $\mathrm{mm}$ compr., tubo 3-3,1 mm compr., incluso; disco nectarífero ausente; ovário 0,9-1 $\mathrm{mm}$ compr., glabro. Legumes 10-12x1,5-2,5 cm, estreitamente oblongo, esparsamente rugoso, margens expandidas, glabros; 10-11 sementes, 6-6,5×3,5-5 $\mathrm{mm}$, elípticas, marrom, pleurograma basal ou central, formato de $\mathrm{U}$.
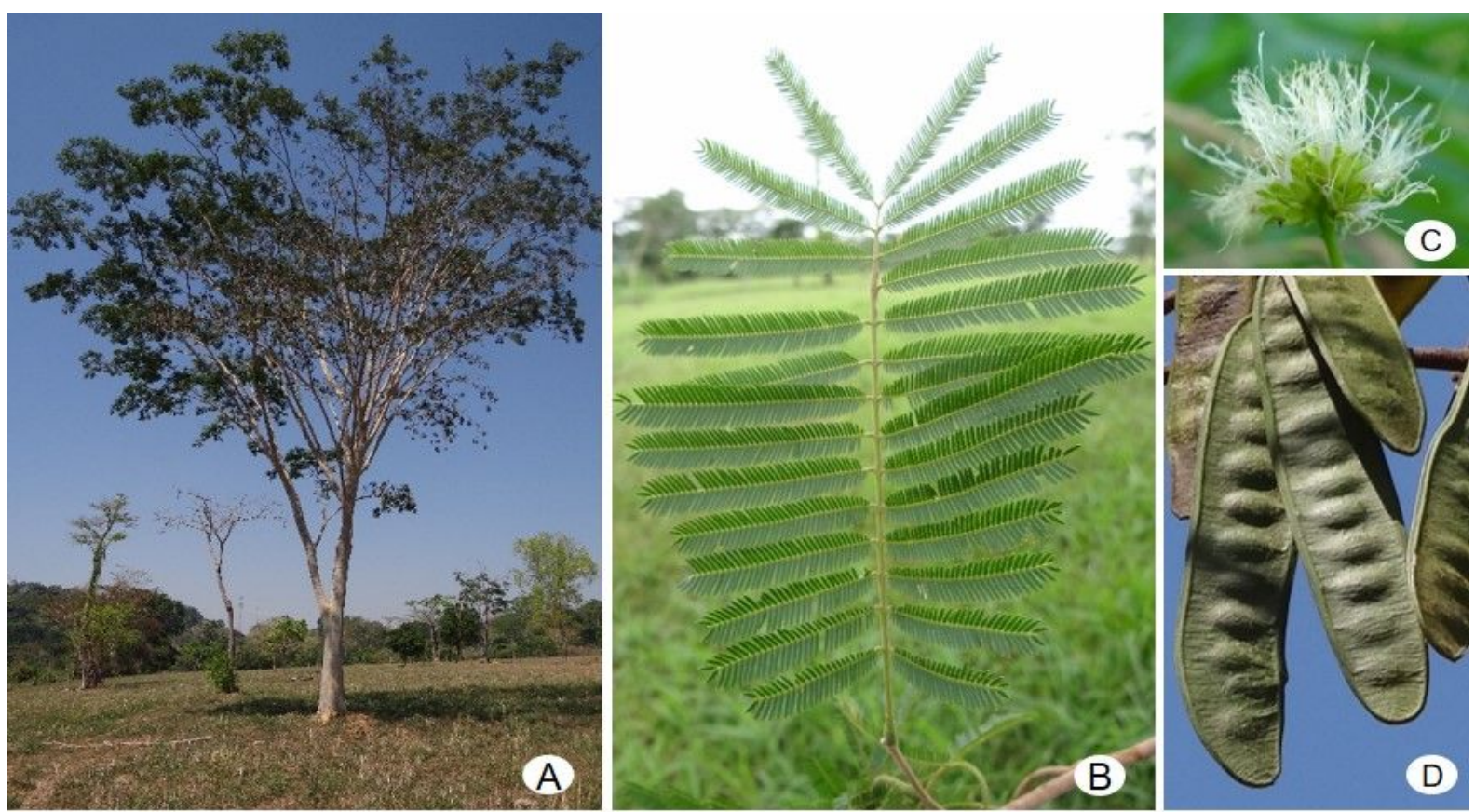

FIGURA 5. Albizia niopoides var. niopoides: A, hábito; B, folha; C, inflorescência; D, frutos. 
A espécie não é endêmica do Brasil (BARNEBY; GRIMES, 1996). No Brasil ocorre na região Norte, nos estados do Acre, Pará, Rondônia e Tocantins, no Nordeste, nos estados da Bahia, Ceará, Maranhão e Piauí, no Centro-Oeste, no Distrito Federal e nos estados de Goiás, Mato Grosso do Sul e Mato Grosso, no Sudeste, nos estados de Minas Gerais, Rio de Janeiro e São Paulo, e na região Sul, nos estados do Paraná, Rio Grande do Sul e Santa Catarina, nos domínios fitogeográficos da Amazônia, Cerrado, Mata Atlântica e Pampa (BFG, 2018). A madeira é empregada para forros, caixotaria e confecção de objetos leves, como brinquedos e lápis; a árvore pode ser empregada na arborização de praças públicas e grandes jardins; é pioneira de rápido crescimento e excelente para reflorestamento misto de áreas degradadas (LORENZI, 2008). A espécie é conhecida popularmente por fava-dentinho (FARIA; LIMA, 2002).

Material examinado: Mato Grosso. Alta Floresta: Fazenda Modelo, 06/X/2007, fl., Melo J. A. M. et al. 50 (HERBAM), comunidade São Bento, Chácara do Zeca 07 VIII2018, fr., A. S. S. Silva et al. 01 (HERBAM), 07 VIII 2018, fr., A. S. S. Silva et al 02 (HERBAM), 18XI2018, fl., J. M. Fernandes 1546 (HERBAM), 10XI2018, fl., J. M. Fernandes 1547 (HERBAM), 10XI2018, fl., J. M. Fernandes 1548 (HERBAM).

6. Albizia pedicellaris (DC.) L. Rico, Novon 9(4): 555. 1999. Figura 6.

Árvores, 15-20 m alt. Folhas 6-8 pares de pinas; pecíolo 1,5-3,7 cm compr., puberulento; nectário na região mediana do pecíolo ou pouco abaixo do primeiro par de pinas e foliólulos, sésseis ou raramente subsésseis, verruciformes, elípticos; raque 5-10 cm compr., puberulenta; foliólulos 21-31 pares por pina, $6-10 \times 2-2,5 \mathrm{~mm}$, estreitamente elípticos, base assimétrica, ápice arredondado ou agudo, face adaxial glabra e abaxial serícea ou esparso serícea. Flores laterais pediceladas, pedicelo 4$6 \mathrm{~mm}$ compr., campanulado, puberulento; cálice 2-2,2 mm compr., campanulado, puberulento; corola 5,1-5,6 mm compr., campanulada, puberulenta; androceu 13-14 estames, 17-26 mm compr., tubo 2-2,3 mm compr., incluso; disco nectarífero ausente; ovário $1 \mathrm{~mm}$ compr., ápice truncado, tomentoso. Flores terminais não observadas. Folículos $6,5-13,5 \times 1,8-2,5 \mathrm{~cm}$, estreito elípticos, lenhosos, nervuras transversais retas e pouco evidentes, suturas transversais, margens expandidas, puberulentas; sementes não observadas. 


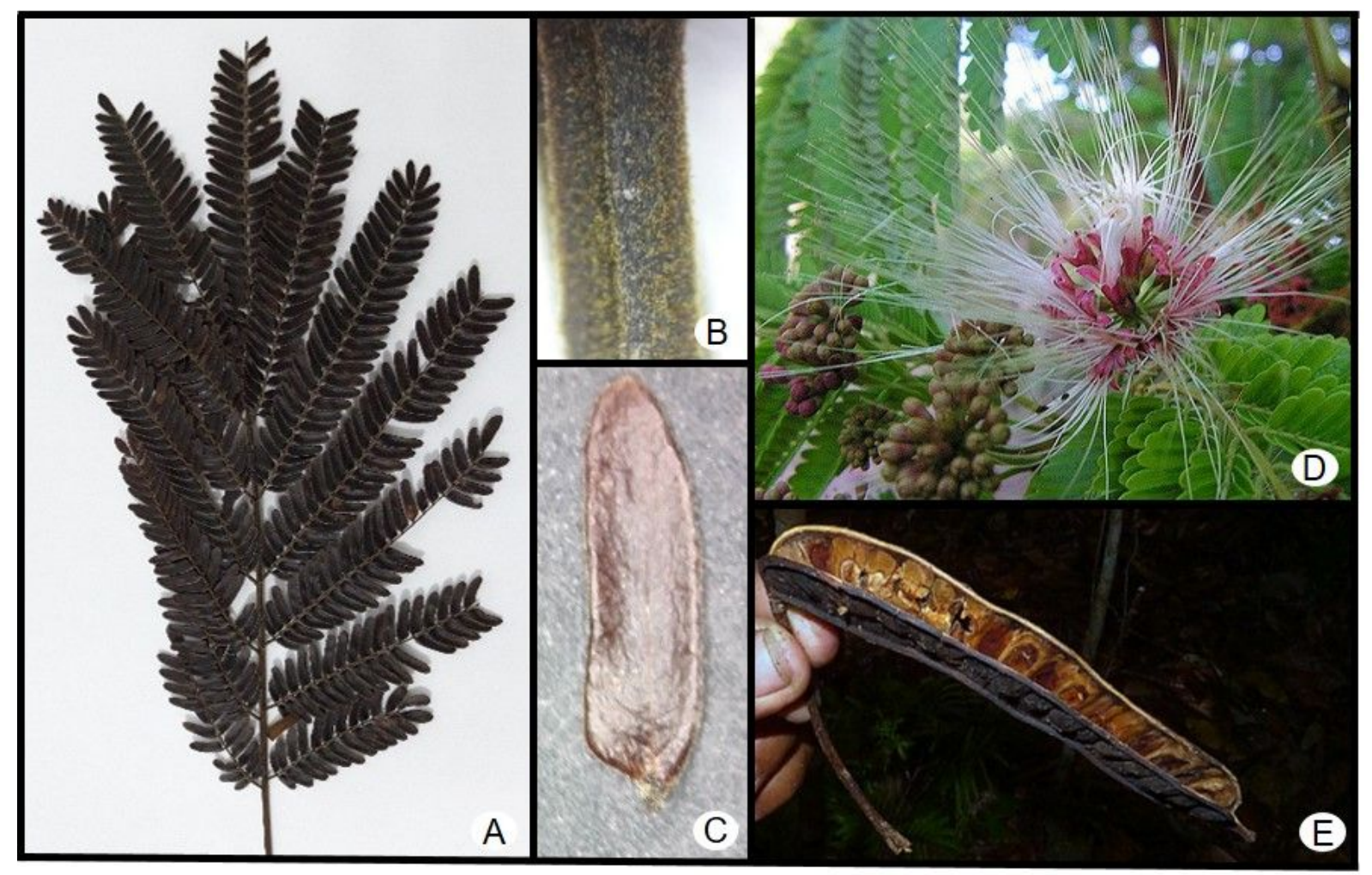

FIGURA 6. Albizia pedicellaris: A, folha; B, indumento do pecíolo; C, foliólulo; D, inflorescência; E, fruto (foto D: T. Leão; foto E: A. Popovkin).

A espécie não é endêmica do Brasil (BARNEBY; GRIMES, 1996). Ocorre na região Norte, nos estados do Acre, Amazonas, Amapá, Pará, Rondônia, Roraima e Tocantins, no Nordeste, nos estados de Alagoas, Bahia, Maranhão, Pernambuco e Rio Grande do Norte, no Centro-Oeste, nos estados do Mato Grosso do Sul e Mato Grosso, no Sudeste, nos estados do Espírito Santo, Minas Gerais, Rio de Janeiro e São Paulo, e no Sul do Brasil no estado do Paraná, nos domínios fitogeográficos da Amazônia, Cerrado e Mata Atlântica (BFG, 2018).

A madeira da espécie é empregada na fabricação de caixotaria, miolo de compensados, forros, brinquedos, cabo de ferramentas e cepas de tamancos; a árvore é rústica e de rápido crescimento, recomendada para a composição de reflorestamento e recuperação de áreas degradadas, como em áreas de mineração (FARIA; LIMA, 2002). Tolera tanto o plantio em áreas sujeitas ao alagamento, quanto em terra firme (FREIRE et al., 2016). É conhecida como paricá de terra firme, cambuí-preto ou juerana-branca (FARIA; LIMA, 2002).

Material examinado: Mato Grosso. Sinop, UHE Sinop, 19/X/2007, fl., C. R. A. Soares 353 (HERBAM). Material examinado adicional: Pará. Jacareacanga: 16/II/2012, fr., C. R. A. Soares et al. 5300 (HERBAM), 24/II/2012, fr., C. R. A. Soares et al. 5369 (HERBAM), 08/XII/2011, fr., C. R. A. Soares et al. 4838 (HERBAM).

7. Albizia subdimidiata (Splitg.) Barneby \& J.W. Grimes var. subdimidiata, Mem. New York Bot. Gard. 74(1): 232. 1996. Figura 7.

Árvores $6 \mathrm{~m}$ alt. Folhas 3 pares de pinas; pecíolo parcialmente impresso, elíptico; raque 3,5-6 cm compr., glabra; foliólulos 8-9 pares por pina, 19-21 x7-9 mm, estreitamente ovado, base arredondada ou semi-cordada, ápice obtuso, faces adaxial e abaxial glabras; palminérveos. Flores não observadas. Legumes 4,5- 
10x0,9-1 cm, estreitamente elípticos ou lineares, geralmente constricto, moniliformes, margens não expandidas, rugosos, glabros; 5-12 sementes, 5-5,9x4,7$5,8 \mathrm{~mm}$, circulares, pleurograma central, fechado.

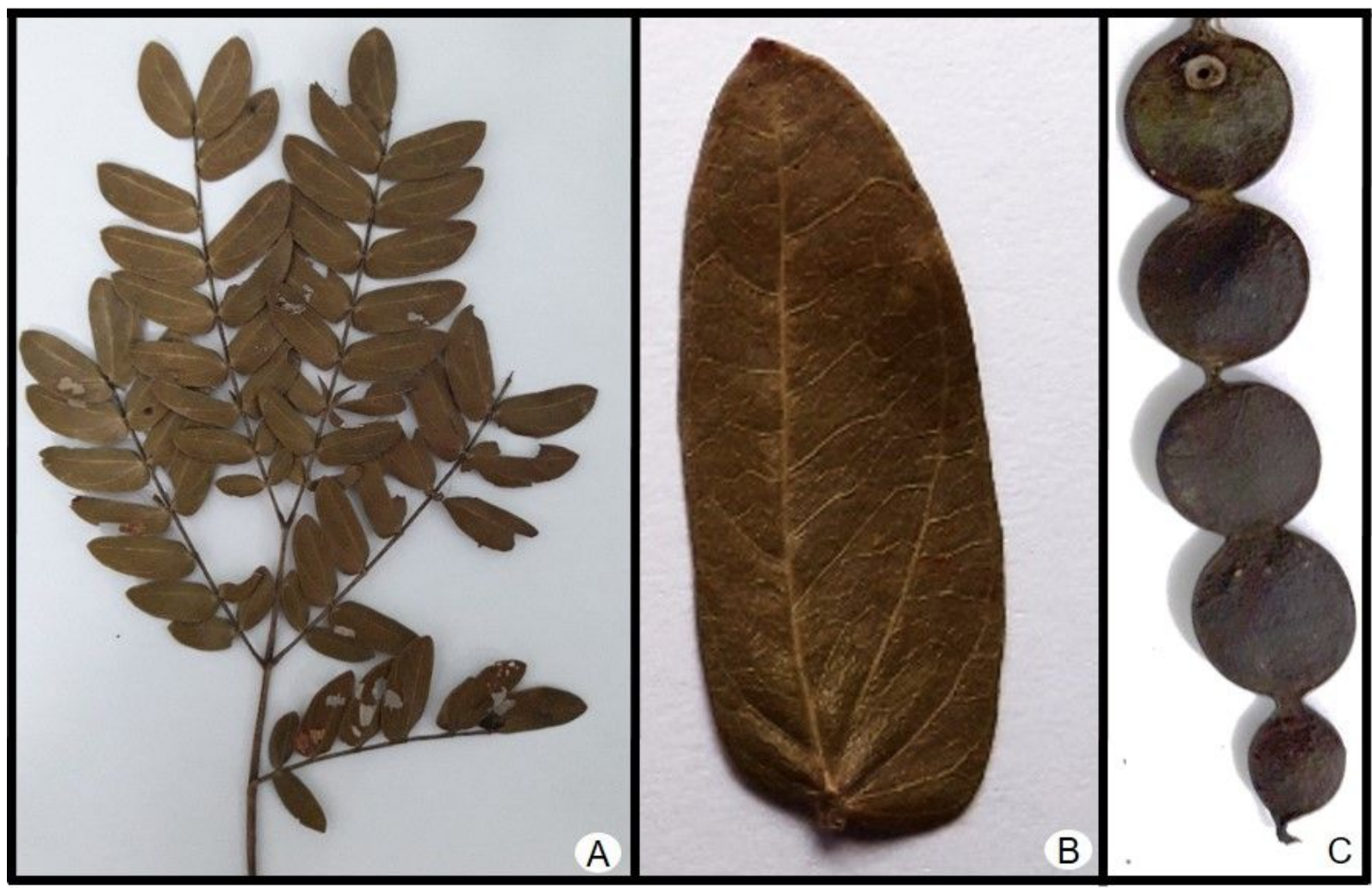

FIGURA 7. Albizia subdimidiata var. subdimidiata: A, folha; B, foliólulo; C, fruto.

A espécie não é endêmica do Brasil (BARNEBY; GRIMES, 1996). No Brasil ocorre na região Norte, nos estados do Acre, Amazonas, Pará, Rondônia e Roraima, no Nordeste, estado do Maranhão, e no Centro-Oeste, no estado de Mato Grosso, no domínio fitogeográfico da Amazônia. É conhecida por paricá de várzea (FARIA; LIMA, 2002).

Material examinado: Mato Grosso. Paranaíta: UHE São Manoel, 25/l/2009, fr., C. R. A. Soares et al. 1933 (HERBAM).

\section{REFERENCIAS}

ABREU, J. T. L.; LOPES, C. R. A. S.; RIBEIRO, R. S.; FERNANDES, J. M. Plantas com risco de extinção depositadas no Herbário da Amazônia Meridional, Alta Floresta, Mato Grosso, Brasil. Enciclopédia Biosfera, v.15, n. 28, p. 1110-1024, 2018.

ADAMS, M. A.; TURNBULL, T. N.; SPRENT, J. I.; BUCHMANN, N. Legumes are different: Leaf nitrogen, photosynthesis, and water use efficiency. Proceedings of the National Academy of Sciences, v. 113, p. 4098-4103, 2016.

APW. Angiosperm phylogeny website. Disponível em: http://www.mobot.org/MOBOT/research/APweb/. Acesso em: 19 de setembro de 2019. 
BARBOSA, A. P. Pharmacologically actives aponins from the genus Albizia (Fabaceae). International Journal of Pharmacy and Pharmaceutical Sciences, v. 6, n. 11, p. 32-36, 2014.

BARNEBY, R. C.; GRIMES, J. W. Silk Tree, Guanacaste, Monkey's Earring. A generic system for the synandrous Mimosaceae of the Americas: part I .Abarema, Albizia and Allies. Memories of The New York Botanical Garden, v. 74, p. 1-292, 1996.

BARROSO, G. M.; MORIM, M. P.; PEIXOTO, A. L.; ICHASSO, C. L. F. Frutos e sementes: morfologia aplicada a sistemática de dicotiledôneas. Viçosa - MG: Imprensa Universitária, 443 p., 1999.

BFG - Growing knowledge: an overview of Seed Plant diversity in Brazil. Rodriguésia, v. 66, n. 4, p.1085-1113, 2015.

BFG - The Brazil Flora Group. Brazilian Flora 2020: Innovation and collaboration to meet Target 1 of the Global Strategy for Plant Conservation (GSPC). Rodriguésia, v. 69, n. 4, p. 1513-1527, 2018

BOUAZIZ, A.; DHIFI, W.; BELLELE, S.; BAHLOUL, N.; OUNI, A.; AL-GARNI, A. K.; MNIF, W. Physico-chemical Characterization, Composition and Potential Uses of Albizia julibrissin Seed Oil. Journal of Essential Oil Bearing Plants, v. 19, p.194199, 2016.

CHAPPILL, J. A. Cladistic analysis of the Leguminosae: the development of na explicit phylogenetic hypothesis. In: CRISP, M.; DOYLE, J. J. (eds.). Advances in Legume Systematic 7: Phylogeny. Royal Botanic Gardens, Kew, p. 1-9, 1995.

FARIA, S. M.; LIMA, H. C. Levantamento de nodulação em leguminosas arbóreas e arbustivas em áreas de influência da Mineração Rio do Norte, Porto Trombetas/PA. Seropédica: Embrapa Agrobiologia, Rio de Janeiro, 18 p., 2002.

FERNANDES, J. M. Ingeae Benth. (Leguminosae, Mimosoideae) no estado de Minas Gerais, Brasil: taxonomia, morfoanatomia de nectários extraflorais e padrões de distribuição geográfica. Tese (Doutorado em Botânica), Universidade Federal de Viçosa, Viçosa, Minas Gerais, 298 p, 2011.

FERNANDES, J. M.; COSTA, R. D.; LOPES, C. A. S. Taxonomia de Inga macrophylla Humb. \& Bonpl. ex Willd. (Leguminosae, Mimosoideae): uma nova ocorrência para Mato Grosso, Brasil. Enciclopédia Biosfera, v.13, n. 24, p. 132913-35, $2016 b$.

FERNANDES, J. M.; GARCIA, F. C. P.; AMOROZO, M. C. M.; SIQUEIRA, L. C.; MAROTTA, C. P. B.; CARDOSO, I. M. Etnobotânica de Leguminosae entre agricultores agroecológicos na Floresta Atlântica, Araponga, Minas Gerais, Brasil. Rodriguésia, v. 65, n. 2, p. 539-554, 2014. 
FERNANDES, J. M.; GARCIA, F. C. P.; SIQUEIRA, L. C.; MAROTTA, C. P. B.; CARDOSO, I. M. Riqueza e a similaridade de Leguminosae em sistemas agroflorestais cafeeiros em Araponga, Minas Gerais. Revista Brasileira de Agroecologia, v. 10, n. 2, p. 75-86, 2016 a.

FERNANDES, J. M.; RODRIGUES, L.; PIVA, J. H.; LOPES, C. R. A. S. Contribuição taxonômica ao estudo do gênero Calliandra Benth. (Leguminosae, Mimosoideae) no estado de Mato Grosso, Brasil. Enciclopédia Biosfera, v.13, n. 24, p. 315-321, 2016c.

FERNANDES, J. M.; SOARES-LOPES, C. R. A.; RIBEIRO, R. S.; SILVA, D.R. Leguminosae no acervo do Herbário da Amazônia Meridional, Alta Floresta, Mato Grosso. Enciclopedia Biosfera, v.11, n. 21, p. 2272-2293, 2015.

FREIRE, J. M.; ATAÍDE, D. H. S.; ROUWS, J. R. C. Superação de dormência de sementes de Albizia pedicellaris (DC.) L. Rico. Floresta e Ambiente, v. 23, n. 2, p. 251-257, 2016.

JUDD, W. S.; CAMPBELL, C. S.; KELLOGG, E. A.; STEVENS, P. F.; DONOGHUE, $M$. J. Sistemática vegetal: um enfoque filogenético. 3 ed. Porto Alegre: Artmed 632 p., 2009.

LEWIS, G. P.; RICO ARCE, M. L. Tribe Ingeae. In: LEWIS, G. P.; SCHRIRE, B. D.; MACKINDER, B. A.; LOCK, J. M. Leguminosae of the World. Royal Botanic Gardens, Kew, Pp.193-213, 2005.

LOPES, C. R. A. S. Herbário da Amazônia Meridional, Mato Grosso (HERBAM). Bioscience, Edição Especial, v. 4, n. 6, p.36-39, 2015.

LORENZI, H. Árvores brasileiras: manual de identificação e cultivo de plantas arbóreas nativas do Brasil. Vol. 2, 5. ed. Nova Odessa - SP: Instituto Plantarum, 384 p., 2002.

LORENZI, H. Árvores brasileiras: manual de identificação e cultivo de plantas arbóreas nativas do Brasil. 5. ed. Nova Odessa - SP: Instituto Plantarum, 384 p., 2008.

LPWG. A new subfamily classification of the Leguminosae based on a taxonomically comprehensive phylogeny. Taxon, v. 66, p. 44-77, 2017.

RADFORD, A. E.; DICKISON, W. C.; MASSEY, J. R.; BELL, C. R. Vascular plant systematics. Harper \& Row, New York, 891 p., 1974.

RICO ARCE, M. L GALE, S.L.; MAXTED, N. A taxonomic study of Albizia (Leguminosae: Mimosoidae: Ingeae) in Mexico and Central America. Anales del Jardín Botánico Madrid, v. 65, n. 2, p. 255-305, 2008. 
SHIRODE, D.; PATEL, T.; ROY, S. P.; JYOTHI, T. M.; RAJENDRA, S. V; PRABHU, K.; SETTY, S. R. Research Article Anti-ulcer properties of $70 \%$ ethanolic extract of leaves of Albizzia lebbeck. Pharmacognosy Magazine, v.4, n. 15, p. 228-231, 2008.

SILVA, J. V.; LOPES, C. R. A. S.; FERNANDES, J. M. Contribuição taxonômica ao estudo do gênero Bauhinia L. (Leguminosae) no Estado de Mato Grosso, Brasil. Enciclopédia Biosfera, v. 13, n. 24, p. 306-314, 2016.

SILVA, R. R.; SOUZA-LIMA, E. S. Fabaceae in the São Francisco River sub-basin, Nova Marilândia, Mato Grosso, Brazil. Biota Neotropica, v. 13, n. 2, p. 297-302, 2013.

SOUZA, S. D.; SPLETOZER, A. G.; RODRIGUES, L.; LOPES, C. R. A. S.; FERNANDES, J. M. Contribuição taxonômica ao estudo do gênero Senna Mill. (Leguminosae, Caesalpinioideae) no Estado de Mato Grosso, Brasil. Enciclopédia Biosfera, v. 13, n. 24, p. 322-330. 2016.

SPRENT, J. I.; ARDLEY, J. K.; JAMES, E. K. Biogeography of nodulated legumes and their nitrogen-fixing symbionts. New Phytologist, v. 215, p. 40-56, 2017. 